\title{
Mechanical Properties Assessment of Laminated Veneer Lumber from Teak Plantation in Laos
}

\section{Khonethong SOUKPHAXAY ${ }^{1, *}$, Khamtan PHONETIP ${ }^{1}$, Latsamy BOUPHA ${ }^{1}$, Lothim SAETERN ${ }^{1}$, Khanxay KHAMMANIVONG ${ }^{1}$ and Fu YU ${ }^{2}$}

${ }^{I}$ Department of Forest Economics and Wood Technology, Faculty of Forestry Science, National University of Laos, Dongdok Campus, Vientiane, Lao

${ }^{2}$ College of Materials and Engineering, Nanjing Forestry University, China

('Corresponding author's e-mail: khone_soukphaxay@yahoo.com)

Received: 9 March 2019, Revised: 7 November 2019, Accepted: 28 November 2019

\begin{abstract}
The objective of this study was to investigate the most influenced levels of pressure and length of time on modulus of rupture (MOR) and modulus of elasticity (MOE) of teak laminated veneer lumber (LVL). Teak LVL was taken from the Faculty of Forestry's forest plantation in Vientiane, Laos. The peeled veneer's thickness was $2.3 \mathrm{~mm}$. The veneer was air-dried until the moisture content reached the range of 6 to $10 \%$. Teak LVL panels were assembled from 9-ply panels of veneer using PL116- Liquid phenol-formaldehyde resin adhesive. The temperature was at $120{ }^{\circ} \mathrm{C}$ at 3 different pressure levels i.e., 1.5, 2 and 2.5 $\mathrm{MPa}$ and levels of time i.e. 9, 11 and $13 \mathrm{~min}$. The experiment was conducted based on ISO16978. Intron Machine Model 5569 was used for the bending test of LVL with a dimension of $20 \times 20 \times 360 \mathrm{~mm}^{3}$. The bending test results on teak LVL showed significantly different MOR and MOE based on length of time and pressure levels of pressing.
\end{abstract}

Keywords: Laminated veneer lumber, Mechanical properties, Teak plantation, PL116-Liquid phenolformaldehyde adhesive

\section{Introduction}

Wood is a hard-fibrous tissue found in many plants. It has many favorable properties such as its processing ability, physical and mechanical properties, aesthetics, and being environmentally and healthfriendly. People have been using wood for many purposes for thousands of years. They primarily used it either as a fuel or construction material for making houses, tools, weapons, furniture, packages, artworks, and paper $[1,2]$.

Additionally, engineered wood is one of the most reliable materials. It has successfully been used in a variety of applications as wood. It is produced from a combination of wood, adhesive, and fiber reinforcement that are bonded together by pressure and heat [3]. There are many factors that affect the mechanical properties of laminated veneer lumber (LVL), such as compression ratio, size, wood species, veneer defects, heat treatment, growth ring characteristics, and density of LVL, etc. For instance, the compression ratio has significant effects on modulus of elasticity (MOE), modulus of rupture (MOR), specific gravity, and thickness swelling of Poplar LVL [4,5]. The strength of wood and other engineering materials is one of the most important factors that was affected by mechanical properties and dynamic loads [6].

Teak (Tectona grandis) wood is the medium strength class upon wood density $\left(565-800 \mathrm{~kg} / \mathrm{m}^{3}\right)$, which is accepted as suitable for all purposes in wood products [7]. Heartwood and sapwood are distinct, yellow-brown on heartwood, straight to fairly interlocked grain, coarse texture, moderately heavy, small 
http://wjst.wu.ac.th

shrinkage, and moderately easy to work with wood machinery. Moreover, teak can be used for housing and interior finishing wood products, i.e., furniture, veneer, and plywood. It is durable timber that is also used in making ship and boat manufacturing, vehicle, packing boxes, musical instruments, and wood mould [8]. The appearance and strength properties of teak wood are respected for a wide variety of wood services depending upon the specific requirements [9]. Ngueho [10], suggested that mature teak trees are not suitable for production in the pulp and paper industry. However, it is better to use young and smallsized teak trees for pulp and paper, particularly small tree cuttings from thinning and pruning [1]. The glue identification No. PL 116-Liquid phenol-formaldehyde is used in hot press adhesive cured at a high temperature ranging from $120-140^{\circ} \mathrm{C}$. The glue is used for the exterior and marine grades plywood [11].

Wanneng [12], compared the mechanical and physical properties of solid teak timber (planted in Luang Prabang province) in different ages $(10,15,20$ and 25 years old). The results showed that there was no significant difference at $95 \%$ confidence. It was also confirmed by [13]. The author found that mechanical properties within tree positions and between trees of the 18 years old teak (from the Training and Model Forest Division of Faculty of Forest Science, Vientiane, Laos) were not significantly different at $95 \%$ confidence.

Teak timber used in Lao wood processing and manufacturing industries is of different ages. It ranged 10 - 30 years old. It is expected that LVL teak would produce more favorable mechanical properties than solid timber. However, it would also depend on the type of adhesive and other parameters, such as pressure, time, and temperature. Therefore, this study aimed to test the MOR and MOE of teak LVL with different pressure rates and a different length of pressing time.

\section{Materials and methods}

Teak logs with diameters at breast height (DBH) of $1.30 \mathrm{~m}$ above ground ranged from 15 to $35 \mathrm{~cm}$ were obtained from the Faculty of Forest Science's Training and Model Forest at Napor Village, Sangthong District, Vientiane Capital, Lao PDR. The teak plantation was planted in 1998 with a spacing of $3 \times 3 \mathrm{~m}^{2}$ [14]. The teak log was debarked by Log Debarker machine, model BBP1400D. Then, teak veneers were peeled by using the Spindle less Peeling Lathe, Model SL1350/3, BSY Industry Company). This machine automatically rotates with the speed of $500-1,200$ revolutions per minute (RPM). A clipping veneer has a dimension of $2.3 \times 450 \times 1,200 \mathrm{~mm}^{3}$ (thickness, width, and length). Then, the length of the veneer was cut into $450 \mathrm{~mm}$ by circular saw MAS machine, Model 806-2. The veneers were then dried to a final moisture content (MC) of 6 - $10 \%$. In order to obtain $20 \mathrm{~mm}$ thick LVL, 9-ply panels were manufactured by DAKE hot press machine, model 44-275. The Experiment and research implementation were conducted at the Wood Science and Wood Products Research Center of the Faculty of Forest Science. Based on the technical team's recommendation, the datasheet, PL 116 of using the PL 116-Liquid phenol-formaldehyde resin adhesive of $43 \%$ solids, was applied at a rate of $320 \mathrm{~g} / \mathrm{m}^{2}$. The hot press parameter was conducted at $120{ }^{\circ} \mathrm{C}$ with a pressure application from 1.2 to $1.5 \mathrm{MPa}$ under the length of pressing time between 10 to $20 \mathrm{~min}$ [11]. This experiment examined the applied pressure beyond the limit recommended in the standard i.e., 1.5, 2.0 and 2.5 $\mathrm{MPa}$, at the pressing time of 9, 11 and $13 \mathrm{~min}$.

The pressed pieces of the LVLs were transformed for bending strength. The sample testing dimension of $20 \times 20 \times 360 \mathrm{~mm}^{3}$ was prepared. There were 180 samples from 9 different panels tested in flat-wise bending according to ISO 16978 standards [15].

The MOR and MOE LVLs specimens were tested using INSTRON CALIBRATION LAB machine model: 5569. This product was from NVLAB CALIBRATION Company (Assembled in the USA) controlled by INSTRON Bluehill software (Version: 2.16). Loading speed was $5 \mathrm{~mm} / \mathrm{min}$. The basic data was summarized by Bluehill software. Statistical analysis was then tested based on an analysis of variance method (one-way ANOVA) manipulated by SPSS (Version: 22.0). 


\section{Results and discussion}

The analysis of variance (ANOVA) indicated that the pressing time and applied pressure affected MOR and MOE of teak LVL products. Tables 1 and 2 showed the comparison of MOR and MOE with affected parameters such as the length of time and the pressure levels.

The results of teak LVL formed at $120^{\circ} \mathrm{C}$ of hot pressing with 3 different length of time $(9,11$, and $13 \mathrm{~min})$ and levels of pressure $(1.5,2.0$, and $2.5 \mathrm{MPa})$. This data showed a significant difference at $\mathrm{P}=$ 0.00 and $\mathrm{P}=0.01$ for the time length and pressure levels, respectively. For instance, the MOR of the boards formed using the pressing time of $13 \mathrm{~min}$ was higher than 9 and $11 \mathrm{~min}$ group by the average MOR value (61.54 MPa \pm 3.64$)$. The pressure, which was a 2.0 MPa group of samples, showed a higher than 1.5 and $2.5 \mathrm{MPa}$ group of samples. The average of MOR is $58.67 \mathrm{MPa} \pm 3.69$, as shown in Figure 1a. Therefore, the MOR of teak LVL should be suitable for manufacturing by $13 \mathrm{~min}$ and $2.0 \mathrm{MPa}$ of pressure.

Table 1 Comparison of MOR in group of effects.

\begin{tabular}{lllllll}
\hline \multicolumn{7}{c}{ MOR (MPa) } \\
\hline Parameters & Source & SS & Df & MS & F & Prob $>$ F \\
\hline Time & Between groups & $1,478.38$ & 2 & 739.19 & 61.74 & 0.00 \\
& Within groups & $2,119.30$ & 177 & 11.97 & & \\
\hline Total & & $3,597.68$ & 179 & 20.09 & & \\
\hline Pressure & Between groups & 117.50 & 2 & 88.75 & 4.59 & 0.01 \\
& Within groups & $3,420.18$ & 177 & 19.32 & & \\
\hline Total & & $3,537.68$ & 179.00 & 108.07 & & \\
\hline
\end{tabular}

In the same conditions of the time and pressure for testing MOE, the results showed a significant difference at $\mathrm{P}=0.00$. For example, the MOE tested at $13 \mathrm{~min}$ was higher than 9 , and $11 \mathrm{~min}$ group of samples. The average was at $2,609.97 \mathrm{MPa} \pm 334.66$, and the pressure of $2.5 \mathrm{MPa}$ was higher than 1.5 and 2.0 MPa. The average was at 2,455.16 MPa \pm 440.05 (Figure 1b). The MOE of teak LVL was increased by increasing both parameters like time and pressure levels.

Table 2 Comparison of MOE in group of effects.

\begin{tabular}{lllllll}
\hline \multicolumn{7}{c}{ MOE (MPa) } \\
\hline Parameters & Source & SS & Df & MS & F & Prob $>$ F \\
\hline Time & Between groups & $6,079,655.91$ & 2 & $3,039,828$ & 56.18 & 0.00 \\
& Within groups & $9,577,732.40$ & 177 & $54,111.48$ & & \\
\hline Total & & $15,657,388.31$ & 179 & $3,093,939$ & & \\
\hline Pressure & Between groups & $1,296,070.99$ & 2 & $648,035.5$ & 7.99 & 0.00 \\
& Within groups & $14,361,317.3$ & 177 & $81,137.38$ & & \\
\hline Total & & $15,657,388.29$ & 179.00 & $729,172.87$ & & \\
\hline
\end{tabular}




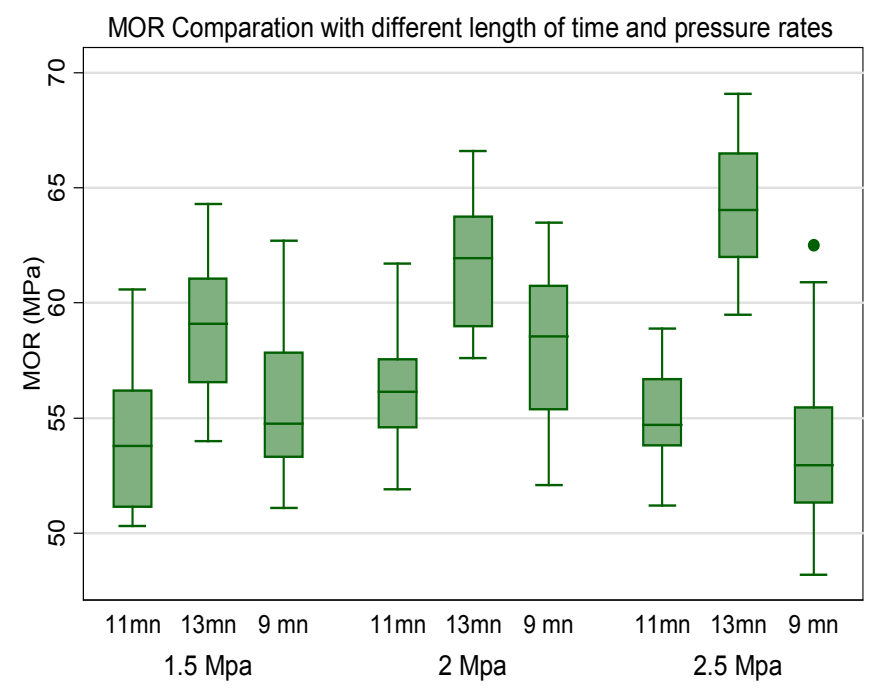

(a)

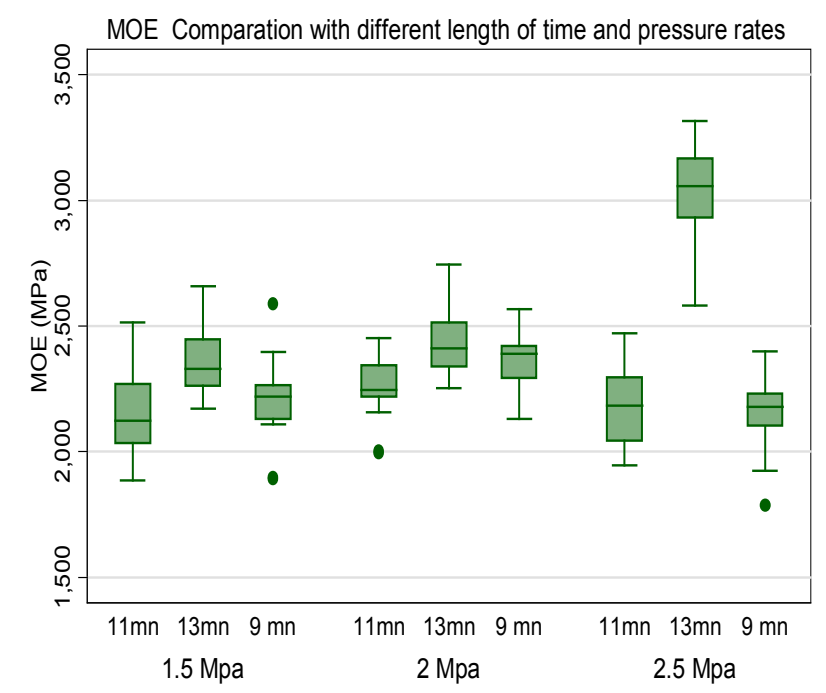

(b)

Figure 1 (a) Comparison of MOR in 3 different length of time and pressure rates affected group, (b) Comparison MOE in 3 length of time and pressure rates affected group.

These results support the previous study by [16]. The author reported that applying different temperature levels at 80,130 , and $180^{\circ} \mathrm{C}$ provided no significant difference in MOR $(107.67,56.40$ and 26.9 $\mathrm{MPa})$ and $\operatorname{MOE}(6,190,5,842.9$ and 4,998.2 MPa) [17], also conducted the same study of LVL from 3 different species Pulai, Sesendok, and Kekebu Hutan, with 2 different layers of veneers 11-ply and 15ply. The flatwise bending test properties (MOR and MOE) of the LVL 15 and 11-ply were tested and compared. The results showed that the number of ply (veneer layer) affected LVL properties found in 
http://wjst.wu.ac.th

MOR and MOE from 3 species. It was the highest in Sesendok species MOR 58.83 MPa, MOE 12,457.58 MPa for 11-ply, and MOR 77.86 MPa, MOE 15,258.95 MPa for 15-ply [17]. The MOR of 11-ply was lower than the current study of about $2.71 \mathrm{MPa}$. Bending property (MOR and MOE) of Peltophorum daysrasid from Borikhamxay province in the central part of Laos was applied with UP adhesive at a rate of $170 \mathrm{~g} / \mathrm{m}^{2}$, with the parameter of pressing at $140{ }^{\circ} \mathrm{C}$ of temperature, $1.2 \mathrm{MPa}$ of pressure, and $13 \mathrm{~min}$. Khounnavonsa [18], reported this finding. The author found that MOR $=171.82 \mathrm{MPa}$ and $\mathrm{MOE}=$ 39,350.68 $\mathrm{MPa}$ given values were also higher than the current study at MOR $61.54 \mathrm{MPa} \pm 3.64$ ) and MOE 2609.97 MPa \pm 334.66 . Wanneng [12], which reported MOR at 10, 15, 20, and 25-year-old found that 111.99, 111.85, 106.30, and 100.69 MPa and MOE 11,972.38, 12,783.67, 12,006.71, and 11,228.05 MPa solid wood properties.

The pressure levels applied beyond the limit mentioned in the standard were significantly different, as clearly showed in Figures $\mathbf{1 a}$ and $\mathbf{1 b}$ indicated at $13 \mathrm{~min}$ of the time level. There was an increased MOR and MOE at different pressure levels from 1.5, 2.0 and 2.5 MPa.

\section{Conclusions}

The bending test results on teak LVL showed significant differences for MOR and MOE based on 3 different pressure levels and length of time. The MOR and MOE increased the pressure rate within 13 mins. This study would say that levels of pressure and length of time of pressing affected MOR and MOE of LVL from the teak plantation in Laos.

\section{Acknowledgements}

The authors would like to express thanks to the Faculty of Forest Science for their financial supports for traveling and accommodation during the International Conference on $4^{\text {th }}$ Industrial Revolution and Its Impacts. Thanks also to the VALTIP3 fellows and the Wood Sciences and Products Research Centre, who allowed us to conduct experiments using their laboratory facilities.

\section{References}

[1] J Bodig and BA Jayne. Mechanical Wood and Wood Composites. Van Nostrand and Reinhold, New York, 1982, p. 666-83.

[2] YX Lui. Woodiness Resource Materials Science. China Forestry, Beijing, China, 2004.

[3] U Meekum and Y Mingmongkol. Experimental design on laminated veneer lumber fiber reinforced composite: Processing parameters and durability. In: Proceedings of the $16^{\text {th }}$ International Conference on Composite Structures. FEUP, Porto, 2011.

[4] HJ Zhang. Compression control and its significance in manufacture and effects on properties of poplar LVL. Wood Sci. Technol. 1994; 28, 285-90.

[5] PS Hing, MT Paridah and A Zakiah. Edgewise bending properties of LVL: Effects of veneer thickness and species. In: Proceedings of USM-JIRCAS Joint International. Technology and Application. 2001, p. 20-2.

[6] BC Bal and İ Bektaş. The effects of some factors on the impact bending strength of laminated veneer lumber. Bioresources 2012; 7, 5855-63.

[7] K Vimal, YS Negi, KK Uniyal and PS Panwar. Physical and mechanical properties of plantationgrown Leucaena leucocephala (Subabul) from Andhra Pradesh and Dehra Dun. Indian For. 2009; 135, 1026-38.

[8] H Naizhang. Identification, Properties and Uses some Southeast Asian Woods. ITTO, Yokohama, Japan, 2005.

[9] A Lahiry. Physical and Mechanical Properties of a Suitable Constructional Timber of Bangladesh. The International Research Group on Wood Preservation, Bangladest, 1997.

[10] Y Ngueho and F Hapla. The effects of growth dynamics on wood quality and utilization of teak and limba. Forstarchiv 2005; 76, 58-64.

[11] Rino. PL 116-Liquid Phenol-formaldehyde Technical Data Sheet. Rino, Vietname, 2018. 
http://wjst.wu.ac.th

[12] P Wanneng. 2011, Wood Property Assessment of Teak (Tectona grandis Linn. F) Plantation of Different Ages Grown in Lao PDR. Ph. D. Dissertation. The University of Melbourne, Vientiane, Laos.

[13] C Han. Wood Physical and Mechanical Properties of Teak (Tectona grandis Linn) from Plantation in Sangthong District, Vientiane Capital. Faculty of Forestry Science, Vientiane, Laos, 2016.

[14] FFS. Faculty of Forestry Science Plantation Management. Vientiane, Laos, 2010.

[15] ISO16978. Wood-Based Panels-Determination of Modulus of Elastricity in Bending and of Bending Strength. Comite Europeen de Normalisation, 2013.

[16] M Nazerian and MD Ghalehno. Physical and mechanical properties of laminated veneer lumber manufactured by polar veneer. J. Agric. Sci. Technol. 2011; 1, 1040-5.

[17] PS Hng and PM Tahir. Bending properties of laminated veneer kumber: Effest of keruing (dipterocapus SPP.) different reinforcement and cyclic-boil-dry-treatment. In: Proceedings of XII Worl Forest Congress. Québec, Canada. 2003.

[18] C Khounnavonsa. Physical and Mechanical Properties of Laminated Veneer Lumber from Peltophorum daysrasid. Faculty of Forest Science, Vientiane, Laos, 2018. 